\title{
The Process of Stimulation of Visual Coordination in Schools with Strabismus and Amblyopia in the Adapted Physical Education Class
}

\author{
Peña Peña Yaimara ${ }^{1}$, Mesa Sánchez Luciano ${ }^{1}$ and Castro Fernández Maida María ${ }^{2}$ \\ ${ }^{1}$ Doctor in Physical Culture Sciences. Faculty of Physical Culture, Manuel Fajardo. University of Camagüey, Ignacio Agramonte Loynaz, Cuba \\ ${ }^{2}$ Bachelor's in Physical Culture, Professor of Physical Education, Antonio Suarez Domínguez Special School of Camagüey, Cuba
}

Submission: October 06, 2018; Published: October 17, 2018

*Corresponding author: Peña Peña Yaimara, Doctor in Physical Culture Sciences, Assistant Professor Faculty of Physical Culture Manuel Fajardo, University of Camagüey, Ignacio Agramonte Loynaz, Cuba, Tel: 53081945; Email: yaimara.pena@reduc.edu.cu

\section{Abstract}

Adapted Physical Education is the process of teaching performance, which must be planned and developed in such a way that it responds to the learning needs of the students, using all the means of Physical Education in order to improve and or normalize the behavior of the scholar with physical, psychic, but also sensory disabilities. In this sense, attention to the peculiarities of schoolchildren diagnosed with strabismus and amblyopia, requires, as an element to be considered, the stimulation of visual-motor coordination, with information currently being limited that reflects the methods, techniques or procedures that could be taken into account to stimulate it in the Adapted Physical Education class.

Keywords: Stimulation; Strabismus; Amblyopia; Visomotor Coordination; Adapted Physical Education

\section{Introduction}

According to Contreras [1] coordination is the neuromuscular ability to adjust precisely what is wanted and thought according to the image fixed by motor intelligence to the need for movement. The analysis of the previous criterion reveals the importance of the image fixed for the successful result. However, the success of this process can be affected by the decrease in visual acuity and deviation in the ocular axes, which is why they are essential aspects to take into account. While at five months the sighted child extends his hand to reach an object that he has in view, it is around ten months that the child with some type of disability in the visual sensory system begins to extend his hands towards some sound object. For this reason, it is important to offer an audibly attractive environment to provoke the approach and, therefore, the stimulation of visual-motor coordination. In this regard, some researchers define it as:

a) Bimanual movement that, after an established visual impression, is carried out with precision, giving the act a harmonious execution [2].

b) Joint activity of the perceptual with the extremities, more with the arms than with the legs, implying, in addition, a certain degree of precision in the execution of the behavior [3]. c) Use of vision to guide the movements of the hand (reaching, grasping, manipulation) [4].

d) Orderly, functional and precise sequencing of eye-hand, eye-foot movements [5].

e) Ability of the visual system to process the information in order to coordinate and control the movement of the hands [6].

f) Ability to coordinate vision with the movements of the body, which is closely related to literacy, taking into account that when you want to take something are the eyes that guide the hand, the same way when you write are the eyes those who must guide the movement [7].

When analyzing the criteria issued by the previous authors, it can be seen as a coinciding element the execution of movements adjusted by sight control, thus showing the relationship between the visual sensory system and the motor sensory system (handeye and foot-sight), in addition to including the action of the object that could intervene. Of the previous authors, some highlight the manual part and others, the manual and foot. In view of this difference of criteria, the Ramos criterion is assumed in the research [5], constituting the oculo-manual coordination 
and the oculo-podal coordination of the two dimensions to be taken into account, highlighting the importance of the direction of the deviation and the degree of visual acuity, considering that the uptake of the visual stimulus can be affected by the difficulties in one of these aspects.

The visual-motor function comprises the visual perception of the forms, their relations in space, their orientation and the motor expression of the perceived. The capacity for observation and attention are fundamental in the development of this function. It involves the exercise of controlled and deliberate movements that require a lot of precision, especially required in tasks where the eye, hand, fingers, foot are used simultaneously, such as, for example, tear, cut, thread, fit, color, write, throw, catch and hit. In strabismic and amblyopic schoolchildren, the use of the hands is of great importance for the search of information abroad. In this way, the hands of a person with strabismus and amblyopia, in addition to performing their usual function as tools, can become useful and intelligent sensory organs. The brain is more plastic, more adaptable, when the child is small. Therefore, the earlier a child with strabismus and amblyopia can learn to use hands as delicately tuned receivers, the more likely it is that he will make optimal use of his hands to obtain information [8].

For visuomotor coordination it is necessary to process the peripheral information that arrives from the visual sensory system and the information that comes from the receptors of the upper or lower limbs. According to Gutierrez [9], this has as its purpose: precision linked to general balance and muscular independence, skill and dexterity in the hands and feet, adaptation to muscular effort, sensorimotor adaptation (joint action of senses and muscles to regulate the coordination of the movement) and the ideomotor adaptation (mental representation of the gestures to be made). In the elements discussed above, regarding visualmotor coordination, it can be seen that information that reflects the methods, techniques or procedures that could be taken into account to stimulate it in the Adapted Physical Education class is still limited. In this regard, elements are proposed that, in this sense, facilitate the understanding of visual motor coordination and, therefore, its stimulation.

\section{Development}

According to Foster \& Jerusalinsky [10], stimulation is a technique to help the student with problems overcome or moderate its effects. On the other hand, Arango, Infante \& López [11], consider that it is the activity that is granted to living beings for a good development or functioning through rewards or also called stimuli that awaken in the individual the motivation to do something, by affection or by certain methods of exercises. They refer to how organisms perceive incoming stimuli, as such, it is part of the stimulus-response mechanism, it can be described as the response that external events provoke to an individual in the attempt to confront them.

These authors also consider that among the types of stimulation are: labor, affective and physical, referred to the latter to the repetition of certain exercises to heal or develop body parts that are damaged or injured. Early stimulation is also common, aimed at promoting the physical, mental and social abilities of the child, preventing psychomotor retardation, curing and rehabilitating motor disorders, sensory deficits, intellectual disabilities, language disorders and, above all, to achieve the insertion of these children in their environment. Not only applicable in healthy children, but also to correct real or potential disorders in their development, or to stimulate compensatory capacities [12].

The analysis of the above criteria allows to appreciate for this process the importance of the stimuli to which the organism is subjected, be they visual, auditory or tactile. In this sense, Batllori \& Escandell [13], consider that stimulation is always sensory since it can only be stimulated through the senses and, the more senses or information channels we imply in therapy, the better results we will obtain. Being consistent with the above criterion presupposes seeing the stimulation as a multisensory aspect, however, it is valid to emphasize that in order to guarantee an effective stimulation in schoolchildren with strabismus and amblyopia, individual particularities and adaptations to the activity must be taken into account.

According to Batllori \& Escandell [13], multisensory stimulation is aimed at optimizing the living conditions of people with disabilities, working on sensations, perception and sensory skills that are basic human beings. Seeking to improve the assimilation of the sensory information that is offered to them improving their relationship with the environment and their learning. This coincides in concepts and objectives with the theory of Sensorial Integration, aimed at the latter to: promote interaction, development and communication; favor the personal and social situation of the child with disability, improving and developing the psychic and physical conditions; develop and initiate communication strategies and insist on sensory-perceptive abilities adjusted to the possibilities of each child; optimize your well-being. The analysis of the previous objectives allows us to appreciate the relevance of these for the stimulation of visual motor coordination in schoolchildren with strabismus and amblyopia. From a physiological point of view, the theory of Sensorial Integration, by Jean Ayres, relates this process to the human being's capacity to carry out motor actions efficiently in different environments, this was elaborated and developed from the following thought: The more sensory experiences of quality you have or receive from the environment and the body, the more you learn from them and therefore the better the relationship with both; the fewer or more negative experiences one has or receives, the less one knows about the body and the environment and, therefore, the greater the difficulties to interrelate with these [14].

All the information we receive about the world comes to us through our sensory systems. Because many of these processes take place within the nervous system, at an unconscious level, we usually do not realize them. Generally, we are familiar with the channels of taste, smell, sight and hearing, but most do not think that the nervous system also feels the touch, movement, the force of gravity and body position. Just as the eyes detect visual 
information and transmit it to the brain to interpretit, the receptors of the rest of the sensory systems capture the information that has been transmitted to the brain. Sensory integration not only allows us to respond appropriately to incoming sensations, but also guides the way in which we act in the medium. Among the signs of sensory integration dysfunction are coordination problems in gross or fine motor activities [14]. In this sense, Pascual [15] considers it necessary to promote multisensory stimulation as one of the aspects to take into account for the educational approach of schoolchildren with visual impairment, considering auditory and tactile stimulation in a timely manner.

The analysis of the above criteria allows us to appreciate that, in view of the difficulties that schoolchildren present with strabismus and amblyopia in the correct capture of visual information, it is considered appropriate to carry out activities related to fixation, visual tracking, displacement, and coordination visomotor. However, for the stimulation to be effective it is important that the child himself manipulates and explores, without forgetting the possible risks that this entails. According to Borges [16], human motor function works according to a model of self-regulation in which a set of structures are grouped, which, in full operating capacity, guarantee posture and movement. This model includes a receptor mechanism that guarantees the reception of stimuli (sensory motor act). In the previous criterion, to the author's consideration, an important element referring to the full capacity of functioning is addressed, this implies that those who present some type of problem in any of these structures, among these the schoolchildren with strabismus and amblyopia, show difficulties.

In this regard, Zimkin [17] states that in the organism of man, information plays an important role in sensory systems, particularly in the processes of precise regulation of motor functions. Thanks to the feedback that is made through the sensory systems, the central nervous system is continually informed about the nature of the motor action performed. The exclusion of the feedback mechanisms in a given activity, for example, the receptors of the periphery and the center of the retina) significantly impairs and even prevents the performance of many exercises. For its part, the motor sensory system guarantees feedback and informs the central nervous system about the degree of contraction of the muscles, the tension of the tendons and ligaments and the position of the joints. The excitement that arises in the receptors of the motor sensory system runs through the fibers of the first neurons of proprioceptive sensitivity, within these, in the visual thalamus. An important role in improving the effectiveness of the functions of this system, includes signal-instrument information on the characteristics of space and time in the structure of movements [17].

\section{Conclusion}

The analysis of the process of stimulation in the Adapted Physical Education, allows to appreciate that the same one is fractioned, this is because the stimulation of the visual-motor coordination is seen as one more aspect of the coordination and not as an essential element to stimulate in schoolchildren with strabismus and amblyopia, because their own disability causes difficulties in it. It presents a general approach, where the objectives to be worked in this direction are not defined, as well as the methods or procedures that favor this process, based on the relationship between the sensory visual and sensorial motor system, essentially considering the degree of visual acuity and the direction of the deviation, the possible adaptations to be made and the information channels that can intervene in the stimulation. To the author's consideration, the relationship between these aspects can be part of an integral approach that makes possible the stimulation of visual-motor coordination, starting from specifying some requirements that favor this process and that fill the gap in this regard.

\section{References}

1. Contreras 0 (1998) Teaching physical education. A constructivist approach Barcelona, Spain: Inde.

2. Álvarez H (1998) Child psychology. Education. History and analysis Evolution of praxis. Development and growth. Regulation and evaluation. Psychological development. Child areas. Body outline Perceptic discrimination. Perceptual motor behavior. Children.

3. González C (1998) History. Psychomotor education. Methodology. Goals. Functions Brain. Conduct. Psychomotor development. Evolution. Children. Disorders. Weakness. Instability. Maturation.

4. Crawford JD, Medendorp WP, Marotta JJ (2004) Spatial transformations for eye-hand coordination. Journal of Neurophysiology 92(1): 10-19.

5. Ramos D (2009) Visomotor coordination for primary school children.

6. Alter-Rasche D (2014) Activities to help your child develop their handeye coordination. Kidspot.

7. Perdiguer E (2014) Frostig test: Visomotor coordination.

8. Miles B (2001) Speak the language of the hands towards the hands. National Center Helen Keller, School for the Perkins Blind). National Center for the distribution of information about children who are deaf and blind (DB-LINK).

9. Gutierrez M (1991) Psychomotor education and play at school age. Seville, Spain: Wanceulen.

10. Foster 0, Jerusalinsky A (2012) Neuropsychological bases of early stimulation.

11. Arango T, Infante E, López ME (2000) Early stimulation $\left(7^{\text {th }}\right.$ edn.). Bogotá, Colombia: Quebecor wold.

12. Martínez E (1996) Early stimulation: A starting point. Pediatrics 68 (2).

13. Batllori J, Escandell V (2009) 150 stimulation games: activities to accompany the child's development from birth to three years. Barcelona, Spain: Pocket verticals.

14. Moya D, Matesanz B (2012) The theory of Sensorial Integration. Madrid, Spain.

15. Pascual SA (2009) Adapted Physical Activity. Special education. Havana, Cuba: Sports.

16. Borges S (2005) An approach to the psychopedagogical study of special educational needs associated with motor deficiencies. Havana, Cuba: IPLAC.

17.Zimkin NV (1975) Human physiology. Havana, Cuba: ScientificTechnical. 
This work is licensed under Creative Commons Attribution 4.0 License

DOI: 10.19080/JPFMTS.2018.05.555666
Your next submission with Juniper Publishers

will reach you the below assets

- Quality Editorial service

- Swift Peer Review

- Reprints availability

- E-prints Service

- Manuscript Podcast for convenient understanding

- Global attainment for your research

- Manuscript accessibility in different formats

( Pdf, E-pub, Full Text, Audio)

- Unceasing customer service

Track the below URL for one-step submission https://juniperpublishers.com/online-submission.php 